\title{
A FUZZY- AHP APPROACH TO EVALUATE THE CRITERIA OF THIRD-PARTY LOGISTICS (3PL) SERVICE PROVIDER
}

\author{
Stefan Jovčić ${ }^{1}$, Petr Průša ${ }^{2}$, Josef Samson ${ }^{3}$, Dragan Lazarević ${ }^{4}$ \\ 1,2,3 University of Pardubice, Faculty of Transport Engineering, Pardubice, Czech Republic \\ ${ }^{4}$ University of Belgrade, Faculty of Transport and Traffic Engineering, Belgrade, Serbia \\ Received 22 March 2019; accepted 22 April 2019
}

\begin{abstract}
This paper deals with the criteria that should be taken into consideration when making a decision about Third-Party Logistics (3PL) service providers and their evaluation. Not all the criteria is equally important, so it is necessary to evaluate them in order to determine the priority and help the company to make a decision. The criteria for $3 \mathrm{PL}$ assessment were defined by consulting several experts in the field of logistics. It is very important to analyze and evaluate 3PL providers because there are a very large number of providers in the market and for the company it is very important to choose the right one, based on the relevant criteria. The methodology used for evaluation of the criteria is based on Fuzzy-AHP (Analytic Hierarchy Process) approach. This approach combines the Saaty's scale (which gives the value of most importance in the statements-criteria) and fuzzy logic (which deals with the linguistic statements). The main result of the paper is to rank the criteria by importance and direct it for the further research in the field of $3 \mathrm{PL}$.
\end{abstract}

Keywords: Third-Party Logistics (3PL) Service Provider, Fuzzy-AHP approach, 3PL evaluation criteria.

\section{Introduction}

Third-Party logistics (3PL) providers have an important role in the logistics industry and represent a very important link between companies and customers. 3PL is a company organization dealing with the physical movement of a certain goods between two points as well as provision of additional value-added services such as warehousing, packaging, customs etc. More and more companies are moving from their own transport account to the accounts of external business partners (3PL). Nowadays, in the field of logistics, it is difficult to find the right external business partner, since the number of 3PL providers has increased significantly and continues to grow. The other reason is that there is a huge amount of criteria that characterize $3 \mathrm{PL}$ and it is hard to make a decision about its evaluation and selection. It is especially important to pay attention to the criteria that characterize the external logistics partner. Not all criteria are equally important. Different companies are looking for providers through different criteria, all depending on their needs. The firm's competitiveness strategy and its external environment affect the selection criteria for 3PL, stated Menon et al., (2014). The criteria considered in this paper are determined by consulting several experts in the field of logistics.

\footnotetext{
${ }^{1}$ Corresponding author: st55819@student.upce.cz
} 
According to Daugherty et al., (1996) the logistics service capabilities provided by a 3PL should include dedication to emergency assistance, ability to handle changes in environment, flexibility in meeting external needs, providing the emergency services, the ability of proposing solutions to potential problems, helping corporations in implementing cost reduction, analysis of problem solution, responding to unforeseen uncertain needs of operational situations, anticipating transportation problems, proposing counter measures when unable to provide service, and providing service or operational status report. All these possibilities should have a logistics provider in order to be considered professional in the field of logistics. Önüt et al., (2009) emphasized that a company could greatly save costs, time and increase competitive advantage in the market by making the right decision about the logistics service provider. However, due to high competition in the market, it is a challenge when choosing an appropriate logistic provider, especially when bearing in mind that there are various criteria that characterize them. There are lots of factors affecting selection of the service provider according to Akman and Baynal (2014).

To evaluate 3PL service providers in better organizing their selection, a variety number of techniques is used in the literature. For example, Kannon et al. (2009) used the multi-criteria methods in fuzzy environment to select the best 3PL reverse logistics service provider. In research mentioned, the authors combined the TOPSIS method and Fuzzy logic. Yang et al., (2010) conducted the research based on LSP selection for AIR cargo by using the Analytic Network Process (ANP) method. As the main criteria involved are performance, features, reliability, conformance serviceability and perceived quality. Vijavargiya and Dey (2010) used the AHP method for logistics service provider selection in India. They considered the criteria such as cost (inland transportation and ocean/air freight), delivery (schedule flexibility) and value-added services (clearing and forwarding and IT- Track and Trace). Kabir (2012) combined the FuzzyAHP approach with the TOPSIS (Technique for Order Preference by Similarity to Ideal Solution) method for 3PL provider selection. The criteria, such as quality, cost and delivery time were taken into consideration. A group of criteria used to evaluate the performance of Logistics Service Providers is of particular importance in the decision-making process. In the research about fuzzy measures of supplier evaluation under lean concepts, Tsai (2009) used criteria pertaining to the service quality, on-time delivery, reliability of delivery, pre and post customer service, target market responsiveness, organization capability, price, and geographical coverage. Vaidyanathan (2005) developed a framework for evaluating third-party logistics based on the following criteria: price, innovation in services, pre and post customer service, and legal contracts. Control management, cost, employee relationships, and control over providers were the criteria used by Perçin (2008). In research about the selection of a third-party logistics provider, Cooper et al., (2012), used the following criteria: on-time delivery, cost, order accuracy, consistency in invoices, response to a purchase order, orders received, flawless delivery, frequency of damage in transportation, inventory accuracy, inventory rotation, warehouse efficiency, returns, service level, transportation risk, and warehouse risk. Rattanawiboonsom (2014) emphasized the transportation risk and warehouse risk as two main criteria for selecting a third-party 
logistics provider. Guneri et al., (2009) used an integrated Fuzzy-linear programming approach for a supplier selection problem. By analyzing the literature in the field of 3PL provider selection, it may be concluded that different evaluation criteria can be used.

The research paper discusses the importance of the criteria for selecting a third-party logistics provider and provides the methodology based on fuzzy-AHP approach. This methodology is very useful for determining the importance of the criteria. The rest of the paper is organized as follows: Section 2 gives a fuzzy-AHP methodology for solving the evaluation problem. In Section 3, the evaluation criteria for 3PL providers is done by using previously described methodology and the final rank of the criteria is obtained. After this section, there are some concluding remarks.

\section{A Fuzzy-AHP Methodology}

AHP method developed by Saaty (1980) deals with the determination of the relative importance of criteria in multi-criteria decision-making problems. Although conventional AHP takes into account the qualitative criteria assessed by the decision makers, it is not able to depict the ambiguity and vagueness of human thinking. It is much easier for the decision makers to state the preference of the criteria by linguistic statements than by numerical values. Therefore, to solve the hierarchical fuzzy problems a fuzzy AHP method has been developed as a fuzzy expansion of the AHP method. The applicability of the method is proven in the literature by solving various problems using the AHP, in its conventional form or in the fuzzy environment, either alone or in a combination with some other methods (Awasthi et al., 2018; Zečević et al., 2016; Tadić et al., 2015; Mangla et al., 2015; Zečević et al., 2014; Junior et al., 2014; Tadić et al., 2014a; Tadić et al., 2014b; Rezaei \& Ortt, 2013; Tadić et al., 2013a; Tadić et al., 2013b; Tadić et al., 2012).

In this paper, fuzzy-AHP methodology is used to evaluate the criteria for 3PL service provider. The following describes the steps of the method application (Ayhan, 2013).

Step 1. Formulation of the Fuzzy-AHP Saaty's Scale with linguistic terms (table 1) (Kilincci and Onal, 2011).

\section{Table 1}

Fuzzy-AHP Triangular Scale

\begin{tabular}{|c|c|c|}
\hline Classic Saaty's Scale & Linguistic Terms & Fuzzy Scale (Triangular Scale) \\
\hline 1 & Equally preferable & $(1,1,1)$ \\
\hline 3 & Weakly preferable & $(2,3,4)$ \\
\hline 5 & Fairly preferable & $(4,5,6)$ \\
\hline 7 & Strongly preferable & $(6,7,8)$ \\
\hline 9 & Absolutely preferable & $(9,9,9)$ \\
\hline 2 & \multirow{4}{*}{$\begin{array}{l}\text { Values designed for evaluation of } \\
\text { so-called interphase }\end{array}$} & $(1,2,3)$ \\
\hline 4 & & $(3,4,5)$ \\
\hline 6 & & $(5,6,7)$ \\
\hline 8 & & $(7,8,9)$ \\
\hline
\end{tabular}


According to the appropriate linguistic terms, the decision maker uses the given fuzzy number on the right side of the scale. For example, if the decision maker states "Criterion 1 is strongly preferable than Criterion 2" then it takes the fuzzy triangular scale as $(6,7,8)$. On the contrary, in the pairwise comparison matrix of the criteria, comparison of Criterion 2 to Criterion 1 will take the fuzzy triangular scale as $(1 / 8$, $1 / 7,1 / 6)$. The pairwise comparison of the criteria presented in the form of matrix is given in equation 1 .

$\widetilde{P_{k}}=\left[\begin{array}{lllllllll}\tilde{Z}_{11}^{K} & \tilde{Z}_{12}^{K} \ldots & \tilde{Z}_{1 n}^{k} & \tilde{Z}_{21}^{k} \tilde{Z}_{22}^{k} \ldots \tilde{Z}_{2 n}^{k} \ldots & \tilde{Z}_{i j}^{k} \ldots & \tilde{Z}_{n 1}^{k} & \tilde{Z}_{n 2}^{k} & \ldots & \tilde{Z}_{n n}^{k}\end{array}\right]$

Where: $\widetilde{Z}_{i j}^{k}$ indicates the $k$-th decision maker's preference of $i$-th criterion over $j$-th criterion, via fuzzy triangular numbers. Here, the sign " " indicates the triangular number demonstration.

For example, $\tilde{Z}_{12}^{2}$ represents the second decision maker's preference of first criterion over second criterion and equals to $\tilde{Z}_{12}^{2}=$ $(6,7,8)$. If there is more than one decision maker, preferences of each decision maker $\tilde{Z}_{i j}^{k}$ are averaged and $\tilde{Z}_{i j}$ is calculated on the following way, given in equation 2 .

$\tilde{Z}_{i j}=\sum_{k=1}^{k} \frac{\tilde{z}_{i j}^{k}}{k}$

Step 2. According to averaged preferences, pairwise contribution matrix is updated as it shown in equation 3.

$\tilde{P}=\left[\begin{array}{lllllll}\tilde{Z}_{11} & \widetilde{Z}_{12} \tilde{Z}_{1 n} & \tilde{Z}_{21} \tilde{Z}_{22} \tilde{Z}_{2 n} \ldots & \tilde{Z}_{i j} \ldots & \tilde{Z}_{n 1} \tilde{Z}_{n 2} \tilde{Z}_{n n}\end{array}\right]$

where: $\widetilde{P}$ represents pairwise contribution matrix.

Step 3. Geometric mean of fuzzy comparison values. It is done according to Buckley (1985) in equation 4 . $\tilde{t}_{i}=\left(\prod_{j=1}^{n} \tilde{Z}_{i j}\right)^{1 / \mathrm{n}} ; \mathrm{i}=1,2, \ldots \mathrm{n}$

where: $\tilde{t}_{i}$ represents geometric mean of fuzzy comparison values, $\prod_{j=1}^{n} \tilde{Z}_{i j}$ is multiplied of each fuzzy value from pairwise comparison matrix.

Step 4. The fuzzy weights of each criterion

It is shown in equation 5 including the following three sub-steps:

Step 4.1 Find the vector summation of each $\tilde{t}_{i}$

Step 4.2 Find the (-1) power of summation vector. Replace the fuzzy triangular number to make it in an increasing order.

Step 4.3 To find the fuzzy weight of criterion $i\left(\widetilde{W}_{i}\right)$, it is necessary to multiply each $\tilde{t}_{i}$ with this reverse vector.

$\widetilde{W}_{i}=\tilde{t}_{i}\left(\tilde{t}_{1} \oplus \tilde{t}_{2} \oplus \ldots \oplus \tilde{t}_{n}\right)^{-1}=\left\{e W_{i}, f W_{i}, g W_{i}\right\}$

where: $e W_{i}, f W_{i}$ and $g W_{i}$ are obtained fuzzy triangular numbers

Step 5. Since $\widetilde{W}_{i}$ are still fuzzy triangular numbers, they need to be de-fuzzified by Center of Area method. This method is proposed by Chou and Chang (2008), via applying the equation 6 .

$M_{i}=\frac{e \widetilde{W}_{i}+f \widetilde{W}_{i}+g \widetilde{W}_{i}}{3}$

where: $M i$ represents a non-fuzzy number.

Step 6: Now, Mi, calculated beyond in equation 6 is a non-fuzzy number, but it needs to be normalized by following equation 7 .

$N_{i}=\frac{M_{i}}{\sum_{i=1}^{n} M_{i}}$

where: $\mathrm{Ni}$ represents the final weights after normalization. 
These 6 steps are performed to find the normalized weights of both criteria and the sub-criteria. Then by multiplying each subcriteria weight with related criteria, the scores for each sub-criteria is calculated. According to these results, the sub-criteria with the highest score is suggested to the decision maker.

\section{Application of the Proposed Methodology to Evaluate the Importance of Criteria for 3PL Provider Selection}

In this paper, the previously described methodology is used to evaluate the importance of criteria that should be taken into consideration when the company makes a decision about $3 \mathrm{PL}$ provider selection. Several experts in the field of logistics and supply chain management are consulted and based on their opinions the authors have given the weights for all criteria. In other words, not all criteria are equally important. In the continuation of the paper, the criteria that should be of huge importance will be described and evaluated. The authors distinguished the following criteria.

Criterion 1. Total cost of logistics outsourcing - this criterion is one of the most important for a logistics company according to the authors' opinion. In the context of the total logistics cost of outsourcing the authors included transport cost, low cost distribution, cost reduction, cost of warehousing, expected leasing cost and cost savings.

Criterion 2. Delivery - this criterion may be represented by attributes such as delivery speed, on-time delivery rate, accuracy of transit/delivery time, on-time performance, on-time shipment and delivery etc.

Criterion 3. Reliability - this criterion means the ability to perform the promised service dependably and accurately. It should be of huge importance for the company for whom the 3PL service provider provides services.

Criterion 4. Flexibility - this is related to ability to adapt to changing customers' requirements. Keeping flexibility in mind, it will include the ability to meet future requirements, the capacity to accommodate and grow the client's business, the capability to handle specific business requirements, time response capability etc.

Criterion 5. Professionalism - from the authors' point of view, this is also one of the most important criteria when making a decision about exact $3 \mathrm{PL}$ provider. If the $3 \mathrm{PL}$ provider is an expert in providing logistics services, a company will be more confident and easier to cooperate with. This criterion is characterized by attributes such as expertise, competence, and experience. Also, 3PL provider have to show to exhibit sound knowledge of services in the industry, display punctuality and courtesy towards their customers in the way they interact and present to the customers.

Criterion 6. Connection with other transport modes - it is very important to emphasize this criterion. The $3 \mathrm{PL}$ provider will be more respectable from the company if it does not use only one transport mode. The 3PL provider will be more respectable for the company if it does not use only one transport mode. The flow of goods can be even faster and logistics services can be made even cheaper.

Criterion 7. Social responsibility - is an important criterion in every field of business and should not be neglected. According to $\mathrm{Yu}$ (2016) social responsibility means to enterprise behavior that conforms to 
the existing social regulations, values and expectations. The same author also emphasized that businesses, nowadays, want to increase efficiency and reduce costs, while also bearing in mind that "green logistics" is a key theme for the future regarding to social responsibility.

Criterion 8. Reputation - This criterion is more relevant in the initial screening of Third-Party Logistics providers. The opinion of the customers about how good are $3 \mathrm{PL}$ providers is in satisfying their needs is one important factor when the company evaluate and select them.

Criterion 9. Information and equipment system - This criterion is of huge importance for each 3PL provider. This corresponds to physical equipment and IT system that has a 3PL in order to facilitate communication and logistics operations of its customers. It is related to Electronic Data Interchange (EDI), track \& trace technology capabilities, information accessibility, materials handling equipment, security of information system etc.

Criterion 10. Quality-According to experts, this criterion can not be omitted because it encompasses many aspects such as quality of service, commitment to continuous improvement, standard environment issues, risk management etc.

After describing the criteria, the authors approach to their assessment using a wellexplained fuzzy-AHP method in Section 2. First, we do the assessment criteria by using the fuzzy-AHP triangular scale. It is given in table 2 .

\section{Table 2}

Criteria for an Assessment by using Fuzzy-AHP Triangular Scale

\begin{tabular}{|c|c|c|c|c|c|c|c|c|c|c|}
\hline & C1 & C2 & C3 & C4 & C5 & C6 & C7 & C8 & C9 & C10 \\
\hline C1 & $(1,1,1)$ & $(2,3,4)$ & $(3,4,5)$ & $(4,5,6)$ & $(2,3,4)$ & $(4,5,6)$ & $(4,5,6)$ & $(6,7,8)$ & $(2,3,4)$ & $(1,2,3)$ \\
\hline C2 & $(0.25,0.33,0.5)$ & $(1,1,1)$ & $(0.16,0.2,0.25)$ & $(1,2,3)$ & $(2,3,4)$ & $(4,5,6)$ & $(4,5,6)$ & $(6,7,8)$ & $(1,2,3)$ & $(3,4,5)$ \\
\hline C3 & $(0.16,0.2,0.25)$ & $(4,5,6)$ & $(1,1,1)$ & $(6,7,8)$ & $(4,5,6)$ & $(2,3,4)$ & $(6,7,8)$ & $(8,9,10)$ & $(4,5,6)$ & $(2,3,4)$ \\
\hline C4 & $(0.16,0.2,0.25)$ & $(0.33,0.5,1)$ & $(0.13,0.14,0.16)$ & $(1,1,1)$ & $(1,2,3)$ & $(2,3,4)$ & $(4,5,6)$ & $(6,7,8)$ & $(3,4,5)$ & $(5,6,7)$ \\
\hline C5 & $(0.25,0.33,0.5)$ & $(0.25,0.33,0.5)$ & $(0.16,0.2,0.25)$ & $(0.33,0.5,1)$ & $(1,1,1)$ & $(0.25,0.33,0.5)$ & $(2,3,4)$ & $(8,9,10)$ & $(3,4,5)$ & $(5,6,7)$ \\
\hline C6 & $(0.16,0.2,0.25)$ & $(0.16,0.2,0.25)$ & $(0.25,0.33,0.5)$ & $(0.25,0.33,0.5)$ & $(2,3,4)$ & $(1,1,1)$ & $(4,5,6)$ & $(6,7,8)$ & $(1,2,3)$ & $(0.16,0.2,0.25)$ \\
\hline C7 & $(0.16,0.2,0.25)$ & $(0.16,0.2,0.25)$ & $(0.13,0.14,0.16)$ & $(0.16,0.2,0.25)$ & $(0.25,0.33,0.5)$ & $(0.16,0.2,0.25)$ & $(1,1,1)$ & $(2,3,4)$ & $(2,3,4)$ & $(0.13,0.14,0.16)$ \\
\hline C8 & $(0.13,0.14,0.16)$ & $(0.13,0.14,0.16)$ & $(0.1,0.11,0.13)$ & $(0.13,0.14,0.16)$ & $(0.1,0.11,0.13)$ & $(0.33,0.5,1)$ & $(0.25,0.33,0.5)$ & $(1,1,1)$ & $(0.16,0.2,0.25)$ & $(8,9,10)$ \\
\hline C9 & $(0.25,0.33,0.5)$ & $(0.33,0.5,1)$ & $(0.16,0.2,0.25)$ & $(0.20,0.25,0.33)$ & $(0.2,0.25,0.33)$ & $(0.33,0.5,1)$ & $(0.25,0.33,0.5)$ & $(4,5,6)$ & $(1,1,1)$ & $(6,7,8)$ \\
\hline C10 & $(0.1,0.11,0.13)$ & $(0.16,0.2,0.25)$ & $(0.25,0.33,0.5)$ & $(0.14,0.16,0.2)$ & $(0.14,0.16,0.2)$ & $(4,5,6)$ & $(6,7,8)$ & $(0.1,0.11,0.13)$ & $(0.13,0.14,0.16)$ & $(1,1,1)$ \\
\hline
\end{tabular}

The next step proposed by the methodology is to find a fuzzy geometric mean of given values. This is calculated according to equation 4 and it is proposed in Table 3. 


\section{Table 3}

A Fuzzy Geometric Mean Value for Each Criterion

\begin{tabular}{|c|c|c|}
\hline Criterion & $\tilde{t}_{i}$ & Values \\
\hline $\mathrm{C} 1$ & $\mathrm{i}=1$ & $(2.26,3.37,4.18)$ \\
\hline $\mathrm{C} 2$ & $\mathrm{i}=2$ & $(1.37,1.88,2.40)$ \\
\hline $\mathrm{C} 3$ & $\mathrm{i}=3$ & $(1.17,1.53,1.95)$ \\
\hline $\mathrm{C} 4$ & $\mathrm{i}=4$ & $(0.85,1.08,1.46)$ \\
\hline $\mathrm{C} 5$ & $\mathrm{i}=5$ & $(0.64,0.84,1.08)$ \\
\hline $\mathrm{C} 6$ & $\mathrm{i}=6$ & $(0.34,0.39,0.49)$ \\
\hline $\mathrm{C} 7$ & $\mathrm{i}=7$ & $(0.28,0.32,0.39)$ \\
\hline $\mathrm{C} 8$ & $\mathrm{i}=8$ & $(0.50,0.64,0.89)$ \\
\hline $\mathrm{C} 9$ & $\mathrm{i}=9$ & $(0.39,0.46,0.59)$ \\
\hline $\mathrm{C} 10$ & $\mathrm{i}=10$ & \\
\hline
\end{tabular}

Following the sub-steps of the step 4, fuzzy-weights are obtained and presented in Table 4.

\section{Table 4}

Obtained Fuzzy Weights

\begin{tabular}{|c|c|}
\hline$\widetilde{w}_{f 1}$ & $(0.14,0.24,0.38)$ \\
\hline$\widetilde{w}_{f 2}$ & $(0.08,0.13,0.22)$ \\
\hline$\widetilde{w}_{f 3}$ & $(0.15,0.22,0,34)$ \\
\hline$\widetilde{w}_{f 4}$ & $(0.07,0.11,0.18)$ \\
\hline$\widetilde{w}_{f 5}$ & $(0.06,0.08,0.13)$ \\
\hline$\widetilde{w}_{f 6}$ & $(0.04,0.06,0.10)$ \\
\hline$\widetilde{w}_{f 7}$ & $(0.02,0.02,0.04)$ \\
\hline$\widetilde{w}_{f 8}$ & $(0.02,0.02,0.04)$ \\
\hline$\widetilde{w}_{f 9}$ & $(0.03,0.04,0.08)$ \\
\hline$\widetilde{w}_{f 10}$ & $(0.02,0.03,0.05)$ \\
\hline
\end{tabular}

In Table 4, obtained $\widetilde{W}_{i}$ are still fuzzy- This is done by using the equation 6 and triangular numbers, therefore they need to the following table represents a non-fuzzy be de-fuzzyfied by the center of area method. numbers.

\section{Table 5}

De-Fuzzification by Using the Center of Area

\begin{tabular}{|c|c|}
\hline Criterion & Center of Area \\
\hline C1 & 0.25 \\
\hline C2 & 0.14 \\
\hline C3 & 0.23 \\
\hline C4 & 0.12 \\
\hline C5 & 0.09 \\
\hline C6 & 0.20 \\
\hline C7 & 0.02 \\
\hline C8 & 0.02 \\
\hline C9 & 0.05 \\
\hline C10 & 0.03 \\
\hline & 1.16 \\
\hline
\end{tabular}


After this procedure, by using non-fuzzy Mi's, the normalized weights and the rank of each criterion are calculated and given in Table 6.

\section{Table 6}

Obtained Criteria Weights and the Final Rank

\begin{tabular}{|l|l|c|c|}
\hline & Criterion & Weights & Rank \\
\hline C1 & Total cost of logistics outsourcing & 0.22 & 1. \\
\hline C2 & Delivery & 0.12 & 4. \\
\hline C3 & Reliability & 0.20 & 2. \\
\hline C4 & Flexibility & 0.10 & 5. \\
\hline C5 & Professionalism & 0.08 & 6. \\
\hline C6 & Connection with other transport modes & 0.17 & 3. \\
\hline C7 & Social responsibility & 0.02 & 10. \\
\hline C8 & Reputation & 0.02 & 9. \\
\hline C9 & Information and equipment system & 0.04 & 7. \\
\hline C10 & Quality & 0.03 & 8. \\
\hline
\end{tabular}

\section{Conclusion}

Third-Party Logistics service providers represent a very important part of the logistics and supply chain. Nowadays, more and more companies outsource their own activities to $3 \mathrm{PL}$. However, the process of selection of $3 \mathrm{PL}$ is affected by a numerous criteria that each company should take into consideration. Depending on the business the company is dealing with, various types of criteria should be distinguished by the logistics provider that is needed by the company. However, there are some criteria such as cost, delivery, quality etc. that are always significant and considered by the companies which selects the provider. In addition, there are many other criteria for the selection and evaluation of 3PL. Not all criteria are equally important. Companies should consider some criteria in more detail in order to keep business efficiently.

The main objective of this paper is to evaluate the criteria that characterize 3PL service providers. For this reason, the FuzzyAHP methodology is used to evaluate the criteria by importance. This methodology is particularly suitable, because it combines Saaty's scale with Fuzzy logic, which deals with the linguistic terms and statements.

For the evaluation process, 10 criteria are taken into consideration and the authors of this paper came to the following conclusion (given in Table 6): the highest importance while selecting 3PL provider is attributed to the total cost of logistics outsourcing with value of 0.22 . The second and third places are devoted to reliability and connection with other transport modes, respectively. The criterion of delivery with participation of 0.12 is at the fourth place. The criterion related to the flexibility is also of huge importance and participates with the weight of 0.10 . The last five criteria related to the professionalism, Information and equipment system, quality, reputation and social responsibility respectively, should not be neglected, but in this paper, there are lesser values attached to them.

This paper gives an insight into the evaluation criteria problem for 3PL selection. 
Future research should be done to select the best 3PL service provider for outsourcing activities. A direction for future research may be a further adjustment of the methodology. The selection of the $3 \mathrm{PL}$, based on our research, should be done by using some of the multi-criteria analysis methods such as TOPSIS, ELECTRE, Promethee etc.

\section{Acknowledgements}

This research paper was supported by SGS_2019_010.

\section{References}

Akman, G.; Baynal, K. 2014. Logistics Service Provider Selection through an Integrated Fuzzy-Multi-criteria Decision Making Approach, Journal of Industrial Engineering: 16 pages.

Awasthi, A.; Govindan, K.; Gold, S. 2018. Multi-tier sustainable global supplier selection using a fuzzy AHPVIKOR based approach, International Journal of Production Economics 195: 106-117.

Ayhan, B. M. 2013. A Fuzzy-AHP approach for supplier selection problem: A case study in a gear-motor company, International Journal of Managing Value and Supply Chains 4(3): 11-23.

Buckley, J. J. 1985. Fuzzy hierarchical analysis, Fuzzy Sets Systems 17(1): 233-247.

Chou, S-W.; Chang, Y-C. 2008. The implementation factors that influence the ERP (Enterprise Resource Planning) Benefits, Decision Support Systems 46(1): 149157.

Cooper, O.; Tadikamalla, P.; Shang, J. 2012. Selection of a Third-Party Logistics Provider: Capturing the Interaction and Influence of Performance Metrics with the Analytical Network Process. J.Multi Crit. Decis. Anal. 19: 115-128, doi:10.1002/mcda.489.
Daugherty, PJ.; Stank, TP.; Rogers, DS. 1996. Third-Party Logistics Service providers: purchasers' perceptions, International Journal of Purchasing and Materials Management 32(1): 23-9.

Guneri, A.F.; Yucel, A.; Ayyildiz, G. 2009. An integrated fuzzy-lp approach for a supplier selection problem in supply chain management, Expert Syst. Appl. 36: 9223-9228.

Jonas Yu, C.P. 2016. 3PL Implementing Corporate Social Responsibility in a Closed-loop Supply Chain: A Conceptual Approach Department of Distribution Management. Takming University of Science and Technology 56, Taipei City, Taiwan.

Junior, F.R.L.; Osiro, L.; Carpinetti, L.C.R. 2014. A comparison between Fuzzy AHP and Fuzzy TOPSIS methods to supplier selection, Applied Soft Computing 21: 194-209.

Kabir, G. 2012. Third party logistic service provider selection using fuzzy AHP and TOPSIS method, International Journal for Quality Research 6(1): 71-79.

Kannan, G.; Pokharel, S.; Kumar, P.S. 2009. A hybrid approach using ISM and fuzzy TOPSIS for the selection of reverse logistics provider, Resources, Conservation and Recycling 54(1): 28-36.

Kilincci, O.; Onal, S.A. 2011. Fuzzy AHP approach for supplier selection in a washing machine company, Expert Systems with Applications 38(8): 9656-9664.

Mangla, S.K.; Kumar, P.; Barua, M.K. 2015. Risk analysis in green supply chain using fuzzy AHP approach: A case study. Resources, Conservation and Recycling 104: 375-390.

Menon, M.; McGinnis, M; Ackerman, K. 1998. Selection criteria for providers of third-party logistics services: an exploratory study, Journal of Business Logistics 19(1): 121-137.

Önüt, S.; Kara, S.S.; Işık, E. 2009. Long Term Supplier Selection Using a Combined Fuzzy MCDM Approach: A Case Study for a Telecommunication Company, Expert Systems with Applications 36(2): 3887-3895. 
Perçin, S. 2008. Fuzzy multi-criteria riskbenefit analysis of business process outsourcing (BPO), Inf. Manag. Comput. Secur. 16: 213-234, doi:10.1108/09685220810893180.

Rattanawiboonsom, V. 2014. Effective Criteria for Selecting Third-Party logistics Providers: The Case of Thai Automotive Industry Rattanawiboonsom, World Rev. Bus. Res. 4: 196-205.

Rezaei, J.; Ortt, R. 2013. Multi-criteria supplier segmentation using a fuzzy preference relations based AHP, European Journal of Operational Research 225: 75-84.

Tadić, S.; Zečević, S.; Krstić, M. 2015. Ranking of Logistics System Scenarios Using Combined Fuzzy AHP-VIKOR Model, International Journal for Traffic and Transport Engineering 5(1): 54- 63.

Tadić, S.; Zečević, S.; Krstić, M. 2014a. Ranking of Logistics System Scenarios for Central Business District, Promet - Traffice Transportation 26(2): 159-167.

Tadić, S.; Zečević, S.; Krstić, M. 2014b. Combined fuzzy AHP-TOPSIS model for regional logistics conceptions evaluation, In Proceedings of XLI Symposium on Operations Research (SYM-OP-IS), Divčibare, 311-316.

Tadić, S.; Zečević, S.; Krstić, M. 2013a. Locating city logistics terminal using fuzzy AHP analysis - Case of Belgrade (in Serbian), Tehnika 68(4): 707-716.

Tadić, S.; Zečević, S.; Krstić, M. 2013b. Evaluation of regional logistics conceptions, In Proceedings of $X L$ Symposium on Operations Research (SYM-OP-IS), Zlatibor, 515-521.
Tadić, S.; Zečević, S.; Krstić, M. 2012. City logistics terminal location selection using combined fuzzy AHP and fuzzy TOPSIS analysis, In Proceedings of the International conference on traffic and transport engineering, ICTTE, Belgrade, Serbia, 345-358.

Tsai, W.C. 2009. Fuzzy Measures of Supplier Evaluation under Lean Concepts, J. Oper. Res. Soc. 60: 1005-1011, doi:10.1057/palgrave.jors.2602643.

Vaidyanathan, G. A 2005. Framework for Evaluating Third-Party Logistics, Commun. ACM 48: 89-94, doi:10.1145/1039539.1039544.

Vijayvargiya, A.; Dey, A.K. 2010. An analytical approach for selection of a logistics provider, Management Decision (48)3: 403-418.

Yang, Y.; Hui,V. Y.; Chen, G. 2010. An analytic network process approach to the selection of logistics service providers for air cargo, Journal of the Operational Research Society 61(9): 1365-1376.

Zečević, S.; Tadić, S.; Krstić, M. 2016. Selection of the intermodal transport chain variant using AHP method, In Proceedings of the $3 r$ International Conference on Traffic and Transport Engineering - ICTTE, Belgrade, Serbia, 339-345.

Zečević, S.; Tadić, S.; Krstić, M. 2014. Ranking of logistics system scenarios using combined fuzzy AHP-VIKOR model, In Proceedings of XLI Symposium on Operations Research (SYM-OP-IS), Divčibare, 323-328. 